\title{
Direito Administrativo Ambiental
}

\author{
Eduardo Lobo Botelho Gualazzi \\ (Procurador do Estado de São Paulo. Professor Adjunto de \\ Direito Administrativo da FADUSP).
}

RESUMO: 1. Intersecção entre Direito Administrativo e Meio Ambiente. 2. Normas de proteção ambiental. 3. Direito Administrativo Internacional do Meio Ambiente. 4. Integração administrativa internacional.

\begin{abstract}
Intersecction between Administrative Law and Environment. 2. Statute Law on Environmental Protection. 3. International Administrative Law on Environment. 4. International administrative integration.
\end{abstract}

RIASSUNTO: 1 . Incrocio fra Diritto Amministrativo e Ambiente. 2. Regolamentazioni di protezione dell'ambiente. 3. Diritto Amministrativo Internazionale dell'Ambiente. 4. Integrazione amministrativa internazionale.

UNITERMOS: 1. Proteção ambiental. 2. Integração sistêmica da Administração. 3. Poder de polícia.

O presente estudo visa exclusivamente sintetizar alguns aspectos atinentes ao vasto tema de intersecção entre o Direito Administrativo e o Meio Ambiente.

Meio Ambiente consiste em objeto interdisciplinar, cujo tratamento subsume-se em várias disciplinas jurídicas e extrajurídicas. José Afonso da Silva considera que o meio ambiente é, assim, a interação do conjunto de elementos naturais, artificiais e culturais que propiciam o desenvolvimento equilibrado da vida humana" (Direito Urbanístico Brasileiro), São Paulo, 1981, RT, p. 435). Realça Massimo Severo Giannini que o meio ambiente (somente "ambiente", em Italiano) abrange três ângulos: a) ambiente paisagístico, natural ou histórico; b) ambiente como afluxo de idéias sobre proteção do solo, do ar e de água; c) ambiente como objeto de disciplina urbanística (cf. Ambiente e: saggio sui diversi suoi aspetti giuridici, in Rivista Trimestrale di Diritto Pubblico, $n-2$, p. 680,1974$)$.

Assinala-se a tendência a considerar-se o Meio Ambiente como objeto do Direito Ambiental, que seria um capítulo do Direito Urbanístico. "Enfim, para os administrativistas, as normas de Direito Urbanístico não passariam de nor- 
mas administrativas, especiais ou não, mas sempre referentes ao poder de polícia" (José Afonso da Silva, Direito Urbanístico Brasileiro, São Paulo, 1981, RT, p. 25). O mesmo autor assinala que, "em verdade, o Direito Urbanístico, especialmente no Brasil, forma-se de um conjunto de normas que ainda pertencem a várias instituições jurídicas, parecendo mais adequado considerá-lo, em seu estágio atual, como uma disciplina de síntese, ou ramo multidisciplinar do Direito, que, aos poucos, vai configurando suas próprias instituições" (op. cit., p. 29).

Concordamos com a asserção de José Afonso da Silva sobre Direito Urbanístico, mas com a ressalva de que, a nosso ver, nesse "ramo multidisciplinar do Direito" predomina nitidamente o Direito Administrativo, inclusive o Direito Internacional Administrativo, aspecto a ser melhor explicitado em outro tópico desta síntese.

Se Direito Administrativo é o "ramo do direito público interno que regula a atividade das pessoas jurídicas públicas e a instituiçāo de meios e órgãos relativos à ação dessas pessoas" (José Cretella Júnior, Curso de Direito Administrativo, 8- ed. 1986, Rio de Janeiro, Forense, p. 41) e se "Direito Urbanístico, como ciência, é o ramo do direito público que tem por objeto expor, interpretar e sistematizar as normas e princípios disciplinadores dos espaços habitáveis" (José Afonso da Silva, Direito Urbanístico Brasileiro, 1981, São Paulo, RT, p. 34), pode-se concluir que o Direito Ambiental é o ramo do Direito Público que tem por objeto sistematizar a atuação administrativa das pessoas jurídicas públicas para indução, preservação ou restauração do equilíbrio harmônico dos espaços habitáveis e dos elementos naturais, artificiais e culturais que integram a vida humana, em termos de ordem, higiene, salubridade, tranqüilidade pública e respeito à propriedade, aos direitos individuais ou coletivos e aos interesses difusos.

No Brasil, pode-se asseverar que há duas espécies de normas jurídicas a tutelarem a proteção ambiental: a) as que asseguram a preservação do ambiente cultural, compreendido como patrimônio histórico, artístico, arqueológico e paisagístico; b) as que visam a proteção do ambiente natural, em relação ao risco de deterioração, com realce para o fator poluidor. As normas que visam preservar o ambiente cultural fundamentam-se no artigo 180, parágrafo único, da Constituição da República, bem como, no Estado de São Paulo, no artigo 128 da Constituição Paulista. Por outro lado, as normas que visam a proteção do ambiente natural fundamentam-se no artigo $8^{\circ}$ (XVII, c) da Constituição da República, sendo certo que o parágrafo único desse dispositivo constitucional assegura aos Estados federados cmpetência para "legislar supletivamente" sobre tal matéria, respeitada a lei federal.

Parece conveniente e oportuno, neste passo, considerar-se panoramicamente o Direito Positivo, brasileiro e paulista, atinente à proteção ambiental, em sentido lato. 
$\mathrm{Na}$ área federal do Brasil, os diplomas legais mais relevantes sobre proteção ambiental são os seguintes: a) Decreto no 24.643, de 10 de julho de 1934 Livro II, Título IV (Código das Águas); b) Decreto-lei no 25, de 30 de novembro de 1937 (tutela do ambiente cultural); c) Lei no 3.924, de 26 de julho de 1961 (proteção do ambiente cultural); d) Lei no 4.771, de 15 de dezembro de 1965 (Código Florestal); e) Decreto-lei no 221, de 28 de fevereiro de 1967 (Código de Pesca); f) Lei no 5.318, de 26 de setembro de 1967 ("institui a Política Nacional de Saneamento e cria o Conselho Nacional de Saneamento"); g) Decreto-lei no 1.413, de 14 de agosto de 1975 (controle da poluição do meio ambiente provocado por atividades industriais); h) Decreto $\mathrm{n}^{\mathrm{O}} \mathbf{7 6 . 3 8 9}$, de 3 de outubro de 1975 (medidas de prevenção e controle de poluição industrial); i) Lei $n^{\circ}$ 6.292, de 15 de dezembro de 1975 (proteção ao ambiente cultural); j) Decreto-lei no 3.866, de 15 de dezembro de 1975 (cmplementa o Decreto-lei no 25/37); I) Decreto no 81.107, de 22 de dezembro de 1977 (elenco de atividades consideradas de alto interesse para o desenvolvimento e a segurança nacional, para os efeitos do Decreto-lei no 1.413/75); m) Lei no 6.803, de 2 de julho de 1980 (diretrizes básicas para o zoneamento industrial nas áreas críticas de poluição); n) Lei no 6.902, de 27 de abril de 1981 (criação de Estações Ecológicas, bem como de Áreas de Proteção Ambiental); o) Lei no 6.938, de 31 de agosto de 1981 (dispõe sobre a Política Nacional do Meio Ambiente, seus fins e mecanismos de formulação e aplicação, bem como cria o Conselho Nacional do Meio Ambiente).

Com certeza, o diploma federal mais relevante do Brasil, no âmbito do Direito Ambiental, é a Lei federal no 6.938, de 31 de agosto de 1981, pois estabelece a Política Nacional do Meio Ambiente, seus fins e mecanismos de formulação e aplicação, constitui o Sistema Nacional do Meio Ambiente, cria o Conselho Nacional do Meio Ambiente e institui o Cadastro Técnico Federal de Atividades e Instrumentos de Defesa Ambiental. De acordo com este diploma legal federal, a Política Nacional do Meio Ambiente "tem por objetivo a preservação, melhoria e recuperação da qualidade ambiental propícia à vida, visando assegurar, no País, condições ao desenvolvimento sócio-econômico, aos interesses da segurança nacional e à proteção da dignidade da vida humana" (art. $2^{\circ}$, caput). Para tanto, a Política Nacional do Meio Ambiente assenta-se em dez princípios, entre os quais se realçam os seguintes: a) "ação governamental na manutenção do equilíbrio ecológico, considerando o meio ambiente como um patrimônio público a ser necessariamente assegurado e protegido, tendo em vista o uso coletivo"; b) proteção dos ecossistemas; c) controle e zoneamento das atividades poluidoras; d) desenvolvimento de tecnologias ambientais; e) "educação ambiental a todos os níveis do ensino". Entre as definições constantes nesta norma federal, é mister atentarmos para as de: a) meio ambiente: "o conjunto de condições, leis, influências e interações de ordem física, química e biológica, que permite, abriga e rege a vida em todas as suas formas"; b) poluição: "a degradação da qualidade ambiental resultante de ati- 
vidades que direta ou indiretamente prejudiquem a saúde, a segurança e o bemestar da população, criem condições adversas às atividades sociais e econômicas, afetem desfavoravelmente a biota, afetem as condiçōes estéticas ou sanitárias do meio ambiente ou lancem matérias ou energia em desacordo com os padrões ambientais estabelecidos". No artigo 60, a Lei federal no 6.938 , de 31 de agosto de 1981, prevê que "os órgãos e entidades da União, dos Estados, do Distrito Federal, dos Territórios e dos Municípios, bem como as Fundaçōes instituídas pelo Poder Público, responsáveis pela proteção e melhoria da qualidade ambiental, constituirão o Sistema Nacional do Meio Ambiente - SISNAMA": neste dispositivo legal divisa-se um exemplo concreto daquele princípio da integração sistêmica da Administração, que deduzimos e definimos como a necessidade de incutir-se nos entes administrativos a consecução dos fins do aparelhamento administrativo do Estado, para assegurar-se o fluxo harmônico e unidirecional das atividades administrativas públicas (cf. nosso Serviços Comerciais, Industriais e Internacionais do Estado, 1985, São Paulo, RT, p. 33). Entre os instrumentos da Política Nacional do Meio Ambiente, o artigo 9ㅇ da Lei federal no 6.938, de 31 de agosto de 1981, alinha os seguintes: I - o estabelecimento de padrões de qualidade ambiental; II - o zoneamento ambietal; III - a avaliação de impactos ambientais; IV - o licenciamento e a revisão de atividades efetiva ou potencialmente poluidoras; $\mathrm{V}$ - os incentivos à produção e instalação de equipamentos e a criação ou absorção de tecnologia, voltados para a melhoria da qualidade ambiental; VI - a criação de reservas e estações ecológicas, áreas de proteção ambiental e as de relevante interesse ecológico, pelo Poder Público Federal, Estadual e Municipal; VII - o sistema nacional de informações sobre o meio ambiente; VIII - o Cadastro Técnico Federal de Atividides e instrumentos de defesa ambiental; IX - as penalidades disciplinares ou compensatórias ao não-cumprimento das medidas necessárias à preservação ou correção da degradação ambiental. Patenteia-se que, entre tais instrumentos da Política Nacional do Meio Ambiente, predominam os atinentes ao Direito Administrativo, sobretudo ao poder de polícia, ao Direito Administrativo Disciplinar (nesse contexto, em sentido impróprio), ao Direito Urbanístico e ao Direito Ambiental. Por fim, o artigo 18 da Lei federal no 6.938/81 estatuiu que "são transformadas em reservas ou estaçōes ecológicas, sob a responsabilidade da SEMA, as florestas e as demais formas de vegetação natural de preservação permanente, relacionadas no artigo 20 da Lei no 4.771, de 15 de setembro de 1965 - Código Florestal, e os pousos das aves de arribação protegidas por convênios ou tratados assinados pelo Brasil com outras naçōes": trata-se de lapso em técnica de redação legislativa, pois o Brasil, Estado soberano, somente poderia subscrever convênios, acordos ou tratados com pessoas jurídicas públicas internacionais, em princípio, mormente outros Estados soberanos, jamais com "outras nações", porque as Nações não dispõem de personalidade jurídica internacional, consoante o Direito Internacional Público, não podendo vincular-se por direitos e obrigações, na órbita jurídica.

Ao mencionar-se a legislação federal do Brasil, relativa ao meio ambiente 
e ecologia, torna-se oportuna uma referência sucinta ao jus positum atinente à área nuclear, bem como a áreas correlatas: a) Lei no 4.118, de 27 de agosto de 1962 (dispõe sobre a Política Nacional de Energia Nuclear, cria a Comissão Nacional de Energia Nuclear e dá outras providências); b) Lei no 5.740 , de 1은 de dezembro de 1971 (autoriza a Comissão Nacional de Energia Nuclear CNEN - a constituir a sociedade por ações Companhia Brasileira de Tecnologia Nuclear - CBTN); c) Lei no 6.189, de 16 de dezembro de 1974 (altera a Lei no 4.118, de 27/8/62, e a Lei no 5.740, de 01/12/71, tendo passado a CBTN a denominar-se Empresas Nucleares Brasleiras S/A - NUCLEBRÁS); d) Decreto-lei no 537, de 17 de abril de 1969 (aprova o Acordo de Cooperação sobre a Utilização Pacífica da EnergiaNuclear, assinado no Rio de Janeiro, aos 18 de dezembro de 1968, com a Índia); e) Decreto-lei no 542, de 18 de abril de 1969 (aprova o Acordo de Cooperação sobre a Utilização de Energia Atômica para Fins Pacíficos, assinado em Madrid, aos 27 de maio de 1968, com a Espanha); f) Decreto-lei no 1630, de 17 de julho de 1978 (concede benefícios tributários ao Programa Nuclear Brasileiro); g) Decreto no 39.872, de 31 de agosto de 1956 (cria o Instituto de Energia Atômica, em São Paulo/SP, nos moldes do convênio firmado aos 11/1/1956 entre o Conselho Nacional de Pesquisas e a Universidade de São Paulo); h) Decreto no 56.618, de 27 de julho de 1965 (promulga o Acordo sobre Cooperação no Campo dos Usos Pacíficos da Energia Atômica, com o Paraguai); i) Decreto no 59.251, de 20 de setembro de 1966 (promulga o Acordo de Cooperação no Campo das Utilizaçōes Pacíficas da Energia Atômica, com a Comunidade Européia de Energia Atômica - EURATOM); j) Decreto no 61.517, de 12 de outubro de 1967 (promulga o Acordo de Cooperação para Usos Civis de Energia Atômica, com os Estados Unidos da América); l) Decreto no 62.521, de 15 de abril de 1968 (promulga o Acordo para a Cooperação na Utilização da Energia para Fins Pacíficos, com Portugal); m) Decreto no 63.152, de 22 de agosto de 1968 (promulga o Acordo para a Utilização da Energia Atômica para Fins Pacíficos, com a Suíça); n) Decreto no 65.160, de 15 de setembro de 1969 (promulga o Acordo Geral de Cooperação da Pesquisa Científica e do Desenvolvimento Tecnológico, firmado com a República Federal da Alemanha); o) Decreto no 66.255, de 24 de fevereiro de 1970 (promulga o Acordo sobre Cooperação no Campo dos Usos Pacíficos da Energia Atômica, com a Bolívia); p) Decreto no 71.207, de 5 de outubro de 1972 (promulga o Acordo de Cooperação relativo aos Usos Civis da Energia Atômica, entre o Brasil e os Estados Unidos da América, e a emenda do Acordo, entre a Agência Internacional de Energia Atômica, o Brasil e os Estados Unidos da América, para aplicação de salvaguardas); q) Decreto no 80.266 , de 31 de agosto de 1977 (estabelece reserva de minérios nucleares, de seus concentrados ou de compostos químicos de elementos nucleares, dispõe sobre estoque de material fértil e físsil especial); r) Decreto no 81.414 , de 28 de fevereiro de 1978 (reforma do Estatuto das Empresas Nucleares Brasileiras S/A NUCLEBRÁS); s) Decreto no 82.079, de 3 de agosto de 1978 (promulga o Acordo sobre Cooperação no Campo de Usos Pacíficos da Energia Atômica, éntre o Brasil e o Peru). 
No tocante ao Estado de São Paulo, especialmente ao jus positum paulista, os textos legais mais relevantes, sobre meio ambiente e ecologia, são os seguintes: a) Lei no 2.182, de 23 de julho de 1953 ("estabelece normas tendentes a evitar a contaminação e poluição das águas litorâneas ou interiores, correntes ou dormentes"); b) Lei no 3.068, de 14 de julho de 1955 (dá nova redação aos artigos 1ํ e 4 da Lei no 2.182, de 23 de julho de 1953); c) Decreto no 45.231, de 16 de setembro de 1965 ("estabelece normas para os lançamentos residuários industriais em cursos d'água"); d) Decreto-lei no 211, de 30 de março de 1970 ("dispõe sobre normas de promoção, preservação e recuperação da saúde, no campo de competência da Secretaria de Estado da Saúde"); e) Decreto-lei no 232, de 17 de abril de 1970 ("dispōe sobre a criação, como entidade autárquica, da Superintendência de Saneamento Ambiental - SUSAM"); f) Lei no 118, de 29 de junho de 1973 ("autoriza a constituição de uma sociedade por ações, sob a denominação de CETESB - Companhia Estadual de Tecnologia de Saneamento Básico e de Controle de Poluição das Águas"); g) Lei no 898 , de 18 de dezembro de 1975 ("disciplina o uso do solo para a proteção dos mananciais, cursos e reservatórios de água e demais recursos hídricos de interesse da Região Metropolitana da Grande São Paulo"); h) Lei no 997, de 31 de maio de 1976 ("dispõe sobre o controle da poluição do meio-ambiente"); i) Lei no 1.172 , de 17 de novembro de 1976 ("delimita as áreas de proteção relativas aos mananciais, cursos e reservatórios de água, a que se refere o artigo $2^{\circ}$ da Lei no 898, de 18 de dezembro de 1975, estabelece normas de restrição de uso do solo em tais áreas e dá providências correlatas"); j) Lei no 1.817, de 27 de outubro de 1987 ("estabelece os objetivos e as diretrizes para o desenvolvimento industrial metropolitano e disciplina o zoneamento industrial, a localização, a classificação e o licenciamento de estabelecimentos industriais na Região Metropolitana da Grande São Paulo"); l) Lei no 2.090, de 27 de agosto de 1979 ("proíbe a instalação e funcionamento de indústrias de alto risco poluidor na bacia de drenagem do Rio Paranapanema"); m) Lei no 2446, de 12 de setembro de 1980 ("restringe as atividades industrias nas áreas de drenagem do Rio Piracicaba"); n) Lei no 4.055, de 4 de junho de 1984 (" declara área de proteção ambiental a regiāo urbana e rural do Município de Cajamar"); o) Decreto no 22.717, de 21 de setembro de 1984 ("declara Área de Proteção Ambiental da Serra do Mar"); p) Decreto-lei no 250, de 29 de maio de 1970 (cria, como entidade autárquica, o Instituto de Energia Atômica - IEA, associado à Universidade de São Paulo). A presente listagem de textos legais estaduais, do Estado de São Paulo, visa a fornecer o painel evolutivo da matérias atinente à proteção ambiental, nos últimos trinta e cinco anos, sendo certo que alguns dispositivos legais das normas mais antigas já se encontram revogados. Verifica-se, outrossim, que a legislação estadual, nessa matéria, é fragmentária, quase casuística: ao contrário do que se verifica na área federal do Brasil, o Estado de São Paulo não apresenta uma norma fundante, unificadora e sistematizadora, como a Lei federal $\mathrm{n}$ - 6.938, de 31 de agosto de 1981. Contudo, a norma estadual que mais se aproxima daquele paradigma federal de sistematização é a Lei estadual no 997, de 31 de maio de 1976 ("dispõe sobre o controle da poluição do meio-am- 
biente"), paradoxalmente anterior à Lei federal no 6.938/81. O artigo 1º da Lei estadual no $997 / 76$ instituiu o Sistema de Preservação e Controle da Poluição do Meio-Ambiente e o artigo $2^{\circ}$ - desta lei definiu poluição do meio-ambiente, como "a presença, o lançamento ou a liberação, nas águas, no ar ou no solo, de toda e qualquer forma de matéria ou energia, com intensidade, em quantidade de concentração e com características em desacordo com as que forem estabelecidas em decorrência desta Lei, ou que tornem ou possam tornar as águas, o ar ou solo impróprios, nocivos ou ofensivos à saúde, inconvenientes ao bem-estar público, danosos aos materiais, à fauna e à flora, prejudiciais à segurança, ao uso e gozo da propriedade e às atividades normais da comunidade". Nos termos da Lei estadual $n=997 / 76$, todo o controle sobre poluição, a priori e a posteriori, fundamenta-se em figurae juris administrativas: licenças, cassação de licenças, interdiçōes, penalidades administrativas, multas administrativas e fiscalização (preventiva e repressiva), no âmbito do poder de polícia estadual.

A seguir, cumpre explicitar-se, sempre em síntese, quais são os instrumentos, os meios de atuação, os institutos jurídicos que possibilitam a atividade público-administrativa de proteção ao meio-ambiente.

O II Plano Nacional de Desenvolvimento alinhou os instrumentos jurídico-preventivos de proteção ambiental,que atuam por meio de fixação de políticas específicas, em três âmbitos: a) política de meio ambiente na área urbana, para evitar a ação poluidora no ar e na água; b) política de preservação dos recursos naturais do País, utilizando corretamente o potencial de ar, água, solo, subsolo, flora e fauna; c) política de defesa e proteção da saúde humana. Nessa tripartição, salientou a "significação das políticas de uso do solo, urbano e rural, dentro de zoneamento racional, e de reflorestamento, a serviço dos objetivos de desenvolvimento e defesa do meio ambiente".

"Os meios repressivos são de dois tipos: a) administrativos, consistentes 1) no estabelecimento de medidas de emergência no caso de risco de vida; 2) em determinar a suspensão da atividade poluidora nos períodos críticos; 3 ) desapropriações; 4) na aplicação de penalidades: advertência, multas, interdição temporária ou definitiva da atividade danosa ao meio ambiente, à preservação florestal etc.; b) judiciais: penais, consubstanciadas apenas no art. 271 do Código Penal, que define o crime de corrupção ou poluição de água potável, de uso comum ou particular, tomando-a imprópria para o consumo ou nociva à saúde, o que, pelo visto, é de estreita aplicação e quase sem nenhuma eficácia, e já discutido art. 42 da Lei de Contravenções Penais, que pune a perturbação do sossego alheio por meio de poluição sonora; 2) civis, mediante ações de perdas e danos em geral, ação cominatória, ação de nunciação de obra nova e, especialmente, de ação popular, cabível nos termos do art. $153, \S 31$, da Constituição Federal e do art. 1으 $\S 1^{\circ}$, da Lei 4.717, de 29.6.1965, para anular atos, comissivos ou omissivos, do poder público e das entidades paraestatais le- 
sivos ao patrimônio artístico, estético, histórico e turístico (José Afonso da Silva, Direito Urbanístico Brasileiro, 1981, São Paulo, RT, p. 478).

Entre tais instrumentos, ademais, o tombamento merece menção específica, por tratar-se do instituto jurídico-administrativo que melhor protege, na maioria dos casos, o patrimônio artístico, estético, histórico, turístico e arqueológico. Segundo José Cretella Júnior, "os traços característicos que permitem o delineamento do regime jurídico do tombamento podem ser assim enunciados: a) definição: tombamento é o conjunto legal de restriçōes parcias que o poder público faz a bem particular, móvel ou imóvel, por motivos de interesse público, mencionados em lei; b) natureza jurídica: ato administrativo unilateral, discricionário e constitutivo; c) motivo: causa ou motivo do instituto é o valor que a lei lhe atribui, valor histórico, artístico, paisagístico, arqueológico; d) qualificação: juízo técnico-científico-artístico-histórico que tipifica o bem, enquadrando-o nas hipóteses enunciadas no texto legal; e) inscrição: fato administrativo, operação material do registro ou tombo do bem, em livro apropriado; f) efeitos: limitaçōes parciais ao exercício do direito de propriedade, do tipo non facere (não demolir, não reparar, não alienar, não destruir); g) fundamento: o instituto do tombamento fundamenta-se no poder de polícia do Estado, que possibilita as limitações, em razões de interesse público" (José Cretella Júnior, Do Tombamento no Direito Brasileiro, in Revista da Faculdade de Direito da Universidade de São Paulo, vol. LXX, 1975, p. 96).

Hely Lopes Meirelles assinala "o surgimento das limitaçōes de proteção ambiental, sob o tríplice aspecto de: a) controle da poluição; b) preservação dos recursos naturais; c) restauração dos elementos destruídos" (Direito Administrativo Brasileiro, 8ª ed., 1981, São Paulo, RT, p. 551).

Em sentido lato, de Direito Administrativo, a proteção ambiental exercese pelo poder de polícia, precisamente como defnido pelo artigo 78 da Lei federal n- 5.172 , de 25 de outubro de 1966 , com a redação dada pelo artigo 70 do Ato Complementar no 31, de 28 de dezembro de 1966: "considera-se poder de polícia atividade da administração pública que, limitando ou disciplinando direito, interesse ou liberdade, regula a prática de ato ou abstenção de fato, em razão de interesse público concernente à segurança, à higiene, à ordem, aos costumes, à disciplina da produção e do mercado, ao exercício de atividades econômicas dependentes de concessão ou autorização do Poder Público, à tranqüilidade pública ou ao respeito à propriedade e aos direitos individuais ou coletivos".

Antes de concluir-se o presente estudo, resta considerar-se o aspecto do Direito Administrativo Internacional do Meio Ambiente. Consideramos o Direito Administrativo Internacional como um ramo tridisciplinar do Direito Público, com a seguinte dicotomia de objeto: a) conflito de leis administrativas estatais entre Estados (formalmente atinente ao Direto Internacional Privado; materialmente, ao Direito Administrativo interno); b) integraçāo coordenante 
a transmissão de elementos técnico-científicos e cuja finalidade é a satisfação do interesse público internacional, não necessariamente coincidente com interesses públicos estatais particularizados. Em síntese lapidar, Paul Négulesco sublinhou que, "do mesmo modo como, na vida interno do Estado, o Direito almeja a realização do interesse geral, no domínio da vida internacional o Direito tem como objetivo o interesse da sociedade internacional. $O$ interesse de um Estado aparece aqui como particular, individual, e deve ser subordinado ao interesse geral" (Paul Négulesco, Principes du Droit Internacional Administratif, in Recueil des Cours de l'Académie de Droit International de la Haye, I, tome 51 , Sirey, 1935, p.599). A propósito deste tema, tão fascinante quão pouco conhecido no Brasil, publicamos nosso estudo ADMINISTRAÇĀO INTERNACIONAL, DO ESTADO, in Revista de Direito Administrativo, 161:329-346, julho/setembro de 1985, e Revista Forense, vol. 292, com realce para as seguintes conclusões: a) há um objeto interdisciplinar, entre o Direito Administrativo e o Direito Internacional Público, consistente no serviço público estatal com destinação internacional e no serviço público internacional com destinação estatal, além de áreas específicas do Direito Internacional Público que aplicam Direito Administrativo (sobretudo Direito Administrativo Disciplinar) e áreas do Direito Administrativo que aplicam o Direito Internacional Público e, por exceção, o Direito do Comércio Internacional (de natureza privatística); b) consideramos o Direito Administrativo Internacional com o capítulo de relações administrativas internacionais de serviço público, entre Estados e organismos internacionais (formalmente atinente ao Direito Internacional Administrativo, capítulo do Direito Internacional Público; materialmente, ao Direito Administrativo Internacional, capítulo do Direito Administravivo). Notese que é tridisciplinar apenas o objeto do Direito Administrativo Internacional. Sob aspecto de autonomia científica, não obstante, o Direito Administrativo Internacional metodologicamente se insere, data venia, como capítulo do Direito Administrativo, na qualidade de "Direito interno, projetando-se no Exterior" (terminologia de Oviedo) e recebendo do Exterior, porquanto se flexiona necessariamente à principiologia setorial do Direito Administrativo e não à do Direito Internacional Público ou Privado. Com efeito, no Direito Administrativo Internacional prepondera a concepção de serviço público, típica de Direito Administrativo. $\mathrm{O}$ serviço administrativo integrante abrange somente a integração coordenante de relaçōes administrativas internacionais de serviço público (matéria atípica da Administração - Poder Executivo): não abarca, evidentemente, conflito de leis administrativas estatais entre Estados (matéria de cognição judiciária). Afinal, visa o serviço administrativo integrante do Estado a inserção coordenada (emissiva e receptiva) da Administração Pública interna na Administração Internacional, a interligação do serviço público interno com o serviço público internacional. Não se trata da juridicização de volições e opções políticas de Estados soberanos, matéria típica do Direito Internacional Público (ou da eficácia extraterritorial da potestade estatal, matéria de Direito Internacional Privado), mas de juridicização coordenante (em regra) ou subordinante ( por exceção) de relaçōes administrativas internacionais, cujo objeto é 
do Direito Administrativo que rege juridicamente o serviço público-administrativo integrante do Estado, com destinação internacional; e consideramos o Direito Internacional Administrativo como o capítulo do Direito Internacional Público que rege juridicamente a atividade administrativa internacional, tanto a relativa à organização interior dos órgãos e entidades internacionais, como a dirigida à coordenação de serviços públicos estatais; embora ainda constituem capítulos de duas disciplinas jurídicas tradicionais (Direito Administrativo e Direito Internacional Público), ambos já regem objeto interdisciplinar comum, têm métodos virtualmente idênticos e conectam-se por um princípio setorial comum, o princípio da integraçāo sistêmica da administração (cf. nosso Serviços Comerciais, Industriais e Internacionais do Estado, 1985, São Paulo, RT, 33 e 125).

Pode-se afirmar, em síntese, que o Direito Administrativo Internacional do Meio Ambiente consiste na parcela do Direito Administrativo Internacional que disciplina a recepção, no âmbito estatal, dos elementos técnico-científicos oriundos da Administração Internacional, sobre matéria ambiental, por meio de relações administrativas internacionais. Longe de constituírem mera especulaçāo teórica ou criação cerebrina, as relações administrativas internacionais, em matéria ambiental, avolumaram-se de modo impressionante, desde o início da década de setènta. Ex facto jus oritur. Direito Administrativo Internacional do Meio Ambiente consiste de matéria que somente poderia ser exaurida em alentado livro. Todavia, a concisão é a melhor homenagem que o jurista pode prestar à Imprensa, sempre aflita com a necessidade de conciliar o espaço escasso da paginação diária com matérias longas e abundantes.

Assim, convém efetuar-se referência meramente pontual, tópica, a respeito da proteção jurídico-ambiental na área internacional. A institucionalizaçāo da luta contra a poluição e da proteção do meio-ambiente foi iniciada com a Resolução no 1346 do Conselho Econômico e Social da Organização das Naçōes Unidas, confirmada em 13 de julho de 1968 por deliberação da Assembléia Geral. Com fundamento naquela decisão, reuniu-se em Estocolmo, em junho de 1972, a Conferência das Nações Unidas sobre o Meio Ambiente, com a participação de 114 Estados. Da Conferência exsurgiram uma "Declaração sobre o Meio Ambiente", contendo um preâmbulo de sete pontos e vinte e seis princípios, bem como um Plano de Ação, integrado por 109 recomendaçōes. Além do Plano de Ação, a Conferência de Estocolmo recomendou que a Assembléia Geral estabelecesse o Conselho Governativo para Programas de Meio Ambiente, que fixou, em junho de 1973, objetivos políticos gerais e específicos, prioridades programáticas de ação e assistência ininterrupta a Governos, no tocante a assuntos de meio ambiente, para transmissão de informação técnicocientífica, organização de programas de treinamento, apoio a possibilidades institucionais internas e disseminação ampla de tecnologias atinentes a meio ambiente. Naquele Plano de Ação e, especialmente, nas recomendações oriundas do Conselho Governativo para Programas de Meio Ambiente, encon- 
tramos exemplo concreto de relaçōes administrativas internacionais de coordenação, entre a Administraçāo Internacional e a Administração Internacional de Estados soberanos, matéria atinente a Direito Administrativo Internacional e Direito Internacional Administrativo.

A poluição e a proteção ao meio-ambiente foram igualmente objeto de Resoluçōes no âmbito da Comunidade Econômica Européia, verbi gratia: a Resolução no 4, do Conselho da Europa, de 8 de março de 1968; Resolução do Parlamento Europeu, de 14 de fevereiro de 1972, que afirmou a necessidade de exame, pelo órgão comunitário, das medida legislativas que os Países da Comunidade Européia pretendem implantar, para o combate à poluição; Programa de Ação das Comunidades Européias, de 19 de julho de 1973. Nestes exemplos concretos, presenciamos o desenvolvimento do Direito Administrativo Comunitário, novo capítulo do Direito Administrativo Internacional, ainda in fieri.

Ao concluirmos, afirmamos que, a exemplo do que ocorre com o tema do meio ambiente e com outros objetos interdisciplinares, a cada dia se torna mais evidente o absurdo de pretender-se tratar de fatispécies jurígenas sob o ângulo unidisciplinar, sempre verticalizante e exclusivista. A visão unidisciplinar consiste de arraigado costume universitário, que há de ser paulatinamente superado pelo enfoque interdisciplinar, sempre horizontalizante e pluralista. A nível científico, a distinção entre Direito Público Internacional e Interno não é barreira estanque, mas ponte de ligação entre duas margens do mesmo rio - o caudal do internacionalismo monista, do supranacionalismo, da integração comunitária. Por este motivo, será necessário dilatarem-se as fronteiras teórico-doutrinárias do Direito Administrativo, ainda conservadoradamente atreladas às atividades da Administração Pública Interna - Poder Executivo -, como se não existissem as atividades administrativas materiais dos Poderes Legislativo e Judiciário ou as da Administração Internacional e da Administraçāo Comunitária... Portanto, o próprio conceito de Direito Administrativo terá de ser revisto e dilatado, em vista de novíssimos fatos jurígenos e de acordo com critérios científicos que abranjam a integração administrativa internacional e comunitária, sempre considerando-se o ensinamento sublime do saudoso Professor Haroldo Valladão: “O DIREITO NĀO É MONOPÓLIO DO ESTADO" (Paz, Direito, Técnica, Rio de Janeiro, 1959, Livraria José Olympio Editora, p. 16).

São Paulo, 07 de abril de 1987 